\title{
Impact of metabolism and growth phase on the hydrogen isotopic composition of microbial fatty acids
}

\author{
Sandra M. Heinzelmann ${ }^{1 *}$, Laura Villanueva ${ }^{1}$, Danielle Sinke-Schoen ${ }^{1}$, \\ Jaap S. Sinninghe Damsté ${ }^{1,2}$, Stefan Schouten ${ }^{1,2}$ and Marcel T. J. van der Meer ${ }^{1}$ \\ 1 Department of Marine Organic Biogeochemistry, NIOZ Royal Netherlands Institute for Sea Research, Den Burg, \\ Netherlands, ${ }^{2}$ Department of Earth Sciences, Faculty of Geosciences, Utrecht University, Utrecht, Netherlands
}

\section{OPEN ACCESS}

Edited by:

James Cotner,

University of Minnesota, USA

Reviewed by:

Karen G. Lloyd,

Aarhus University, Denmark

Magdalena Rose Osburn,

Northwestern University, USA

Alex Sessions,

California Institute of Technology, USA

*Correspondence:

Sandra M. Heinzelmann, Department of Marine Organic

Biogeochemistry, NIOZ Royal

Netherlands Institute for Sea Research, P.O. Box 59, 1790 AB Den

Burg, Netherlands

sandra.heinzelmann@nioz.n

Specialty section:

This article was submitted to

Aquatic Microbiology,

a section of the journal

Frontiers in Microbiology

Received: 05 November 2014 Accepted: 19 April 2015 Published: 08 May 2015

Citation:

Heinzelmann SM, Villanueva L,

Sinke-Schoen D, Sinninghe Damsté

JS, Schouten S and van der Meer MTJ (2015) Impact of metabolism and growth phase on the hydrogen isotopic composition of microbial fatty

acids. Front. Microbiol. 6:408.

doi: 10.3389/fmicb.2015.00408
Microorganisms are involved in all elemental cycles and therefore it is important to study their metabolism in the natural environment. A recent technique to investigate this is the hydrogen isotopic composition of microbial fatty acids, i.e., heterotrophic microorganisms produce fatty acids enriched in deuterium (D) while photoautotrophic and chemoautotrophic microorganisms produce fatty acids depleted in D compared to the water in the culture medium (growth water). However, the impact of factors other than metabolism have not been investigated. Here, we evaluate the impact of growth phase compared to metabolism on the hydrogen isotopic composition of fatty acids of different environmentally relevant microorganisms with heterotrophic, photoautotrophic and chemoautotrophic metabolisms. Fatty acids produced by heterotrophs are enriched in $D$ compared to growth water with $\varepsilon_{\text {lipid/water }}$ between 82 and $359 \%$ when grown on glucose or acetate, respectively. Photoautotrophs ( $\varepsilon_{\text {lipid/water }}$ between -149 and $-264 \%$ ) and chemoautotrophs ( $\varepsilon_{\text {lipid/water }}$ between -217 and $-275 \%$ ) produce fatty acids depleted in D. Fatty acids become, in general, enriched by between 4 and $46 \%$ with growth phase which is minor compared to the influence of metabolisms. Therefore, the $\mathrm{D} / \mathrm{H}$ ratio of fatty acids is a promising tool to investigate community metabolisms in nature.

Keywords: metabolism, fatty acids, hydrogen isotopic fractionation, growth phase

\section{Introduction}

Microorganisms are key players in all elemental cycles and therefore have a huge impact on their immediate and the global environment (Conrad, 1996; Morel and Price, 2003; Arrigo, 2005; Falkowski and Godfrey, 2008; Muyzer and Stams, 2008; Hügler and Sievert, 2011; Orcutt et al., 2011). In order to comprehend their environmental impact, it is important to characterize and understand their metabolic activities. Several approaches help to understand microbial metabolisms present in different environments. One approach is the isolation or enrichment of microorganisms from a specific environment to test its growth on possible substrates and investigate its metabolic pathways. Unfortunately, the isolation of specific microorganisms can give a biased view of the composition of microbial communities as it has been estimated that only $\sim 1 \%$ of all microorganisms can be enriched, isolated, and cultivated by standard techniques (Amann et al., 1995). Often microorganisms with new metabolic capacities or that are present in the highest abundance have not been isolated (Overmann, 2006). Therefore, studying microbial activity in situ 
becomes necessary in order to understand metabolic dynamics within microbial communities.

For this purpose e.g., stable isotope probing (SIP) can be used to identify specific microorganisms which utilize particular substrates (Nold and Ward, 1996; Radajewski et al., 2000). The specific substrates have to be highly enriched in a stable isotope (e.g., $\mathrm{D},{ }^{13} \mathrm{C},{ }^{15} \mathrm{~N},{ }^{18} \mathrm{O}$ ) for the label to be incorporated by active microorganisms into biomarkers like DNA, RNA and lipids. The labeled biomarkers can be then purified and identified (Boschker et al., 1998; Manefield et al., 2002; Radajewski et al., 2003; Dumont and Murrell, 2005; van der Meer et al., 2005, 2007; Neufeld et al., 2007). The most common approach to characterize the metabolic activity of microbial communities is estimate activity rate measurements of a specific activity (Chapelle and Lovley, 1990; Phelps et al., 1994). An alternative to this is the characterization of functional genes which are involved in different metabolic pathways using messenger RNA (mRNA) and 16S ribosomal RNA (Holmes et al., 2005). This approach allows not only for the identification of members of the community by gene sequence but also their relative abundance by determination of the copy number of that sequence and their metabolic activity by mRNA copy numbers (Corredor et al., 2004; Henry et al., 2004; Holmes et al., 2005; Sharma et al., 2007; Jensen et al., 2008; Agrawal and Lal, 2009; Blazejak and Schippers, 2011; Kong et al., 2012; Akerman et al., 2013). However, all the approaches listed above have their limitations like isotopic cross-labeling, artificial change in both microbial diversity and activity as a result of experiment set-up of incubations, or requires pre-knowledge of gene sequences (Radajewski et al., 2000; Dumont and Murrell, 2005; van der Meer et al., 2005; Cebron et al., 2007; Bowen et al., 2014). An alternative is to use the natural isotopic composition of lipids. For example, carbon isotope discrimination $\left(\delta^{13} \mathrm{C}\right)$ can be used for identification of methanotrophs due to the fact that they produce lipids depleted in ${ }^{13} \mathrm{C}$ compared to other microorganisms (Summons et al., 1994).

Recently it has been shown that the ratio of deuterium to hydrogen $(\mathrm{D} / \mathrm{H}$ or $\delta \mathrm{D})$ of fatty acids reflect the central metabolism of microorganisms (Zhang et al., 2009a). Microbes grown under phototrophic conditions produce fatty acids depleted in D (ranging from -150 to $-250 \%$ ) relative to the growth medium under both oxic and anoxic conditions (Sessions et al., 1999; Chikaraishi et al., 2004; Zhang and Sachs, 2007; Zhang et al., 2009a). Fatty acids of chemoautotrophs are even more depleted in D (ranging from -250 to $-400 \%$ ) relative to the growth medium, independent of the electron donor (Valentine et al., 2004; Campbell et al., 2009; Zhang et al., 2009a). In contrast, organisms grown under heterotrophic conditions, e.g., grown with acetate or glucose as substrate, are relatively enriched in D and range from -150 to $>+200 \%$ regardless of factors such as temperature (Sessions et al., 2002; Zhang et al., 2009a; Dirghangi and Pagani, 2013; Fang et al., 2014). Zhang et al. (2009a) attributed these differences to the $\mathrm{D} / \mathrm{H}$ ratio of nicotinamide adenine dinucleotide phosphate (NADPH), which is generated by a variety of different reactions in different metabolic pathways (each associated with different hydrogen isotopic fractionations) and subsequently used as the main $\mathrm{H}$ source in lipid biosynthesis (Saito et al., 1980; Robins et al.,
2003; Schmidt et al., 2003). The analysis of the D-composition of microbial fatty acids may thus yield insights into the metabolism of individual microbes or microbial communities. Furthermore, the persistence of lipids over geological time periods should allow for the study of microbial metabolisms in the past from sedimentary records. However, not many microbes have yet been analyzed for the hydrogen isotopic composition of fatty acids. Furthermore, other factors than metabolism have been shown to influence the $\mathrm{D} / \mathrm{H}$ ratio of lipids such as temperature (Zhang et al., 2009b; Dirghangi and Pagani, 2013), lipid biosynthetic pathways (Fang et al., 2014), growth rate, growth phase, and salinity (Schouten et al., 2006; Wolhowe et al., 2009; Chivall et al., 2014; M’boule et al., 2014).

In order to improve the reliability of $\delta \mathrm{D}$ of fatty acids as an indicator for the metabolism of microorganisms we evaluated both the effect of metabolism (auto- vs. heterotrophic) and of growth phase (exponential, stationary, and death phase) on the $\delta \mathrm{D}$-values of fatty acids of different microorganisms which are mainly derived from aquatic environments with salinities ranging from almost freshwater or open marine. Thiocapsa roseopersicina and Halochromatium glycolicum are both anaerobic, phototrophic purple sulfur bacteria using hydrogen sulfide as electron donor and found in microbial mat and saline lakes, respectively. Isochrysis galbana is an aerobic, phototrophic haptophyte algae using water as electron donor and common in coastal marine environments. Thiobacillus denitrificans is an anaerobic, chemolithoautotrophic $\beta$-proteobacterium using thiosulfate as electron donor and is common in aquatic environment from freshwater to marine. Finally, a recently isolated Pseudomonas str. LFY10 from Lake Fryxell, Dry Valleys, Antarctica, is investigated which is an aerobic, heterotrophic $\gamma$ proteobacterium using either glucose or acetate as carbon source.

\section{Materials and Methods}

\section{Cultures}

The photoautotrophic purple sulfur bacteria Thiocapsa roseopersicina (DSM-217) and Halochromatium glycolicum (DSM-11080) were grown on a modified Pfenning's medium containing $0.34 \mathrm{~g} \mathrm{NH}_{4} \mathrm{Cl}, 0.34 \mathrm{~g} \mathrm{KH}_{2} \mathrm{PO}_{4}, 0.5 \mathrm{~g} \mathrm{MgSO}_{4} \times 7 \mathrm{H}_{2} \mathrm{O}$, $0.34 \mathrm{~g} \mathrm{KCl}, 0.25 \mathrm{~g} \mathrm{CaCl}_{2} \times 2 \mathrm{H}_{2} \mathrm{O}, 1.5 \mathrm{~g} \mathrm{NaHCO}_{3}, 0.4 \mathrm{~g} \mathrm{Na}_{2} \mathrm{~S} \times 9$ $\mathrm{H}_{2} \mathrm{O}, 0.02 \mathrm{~g}$ vitamin $\mathrm{B}_{12}$, and $1 \mathrm{~mL}$ trace element solution SL-12 (Pfennig, 1965) per liter of distilled water. The $\mathrm{pH}$ was adjusted with $1 \mathrm{M} \mathrm{HCl}$ to $\mathrm{pH}$ 7-7.5. The medium for H. glycolicum was additionally supplemented with $6 \% \mathrm{NaCl}, 0.3 \% \mathrm{MgCl}_{2} \times 6$ $\mathrm{H}_{2} \mathrm{O}$, and $0.05 \% \mathrm{Na}_{2} \mathrm{~S}_{2} \mathrm{O}_{3}$ (final concentration). The cultures were incubated in air tight bottles at $25^{\circ} \mathrm{C}$ and a light intensity of $\sim 1300$ lux of a halogen lamp ( $16 \mathrm{~h}$ light, $8 \mathrm{~h}$ dark).

The chemolithoautotrophic sulfide oxidizer Thiobacillus denitrificans (DSM-12475) was grown on a medium containing $2 \mathrm{~g} \mathrm{KH}_{2} \mathrm{PO}_{4}, 2 \mathrm{~g} \mathrm{KNO}_{3}, 1 \mathrm{~g} \mathrm{NH} 4 \mathrm{Cl}, 0.8 \mathrm{~g} \mathrm{MgSO}_{4} \times 7 \mathrm{H}_{2} \mathrm{O}$, $2 \mathrm{~mL}$ trace element solution SL-4, $5 \mathrm{~g} \mathrm{Na}_{2} \mathrm{~S}_{2} \mathrm{O}_{3} \times 7 \mathrm{H}_{2} \mathrm{O}, 1 \mathrm{~g}$ $\mathrm{NaHCO}_{3}, 2 \mathrm{mg} \mathrm{FeSO} 4 \times 7 \mathrm{H}_{2} \mathrm{O}, 1 \mathrm{~mL} 0.1 \mathrm{~N} \mathrm{H}_{2} \mathrm{SO}_{4}$ per liter of distilled water $(\mathrm{pH}$ 7.0). The trace element solution SL-4 contained $0.5 \mathrm{~g}$ EDTA, $0.2 \mathrm{~g} \mathrm{FeSO}_{4} \times 7 \mathrm{H}_{2} \mathrm{O}, 0.01 \mathrm{~g} \mathrm{ZnSO}_{4} \times 7$ $\mathrm{H}_{2} \mathrm{O}, 3 \mathrm{mg} \mathrm{MnCl} 2 \times 4 \mathrm{H}_{2} \mathrm{O}, 0.03 \mathrm{~g} \mathrm{H}_{3} \mathrm{BO}_{3}, 0.02 \mathrm{~g} \mathrm{CoCl}_{2} \times 6 \mathrm{H}_{2} \mathrm{O}$, $1 \mathrm{mg} \mathrm{CuCl} 2 \times 2 \mathrm{H}_{2} \mathrm{O}, 2 \mathrm{mg} \mathrm{NiCl} 2 \times 6 \mathrm{H}_{2} \mathrm{O}, 3 \mathrm{mg} \mathrm{Na} \mathrm{MoO}_{4} \times$ 
$2 \mathrm{H}_{2} \mathrm{O}$ per liter of distilled water. T. denitrificans cultures were incubated at $25^{\circ} \mathrm{C}$.

The photoautotrophic eukaryote Isochrysis galbana (CCMP 1323) was grown at a salinity of 35.5 practical salinity units (psu) as previously described (M'boule et al., 2014) in $\mathrm{f} / 2$ medium which contained $0.07 \mathrm{~g}$ of $\mathrm{NaNO}_{3}, 0.013 \mathrm{~g}$ of $\mathrm{Na}_{2} \mathrm{HPO}_{4} \times 12$ $\mathrm{H}_{2} \mathrm{O}, 1 \mathrm{~mL}$ of a trace element solution, and $1 \mathrm{~mL}$ of a vitamin solution per $1 \mathrm{~L}$ of sea water (Guillard, 1975). The trace element solution contained per liter of distilled water: $4.36 \mathrm{~g}$ EDTA, $3.15 \mathrm{~g}$ $\mathrm{FeCl}_{3} \times 6 \mathrm{H}_{2} \mathrm{O}, 0.01 \mathrm{~g} \mathrm{CuSO}_{4} \times 5 \mathrm{H}_{2} \mathrm{O}, 0.02 \mathrm{~g} \mathrm{ZnSO}_{4} \times 7$ $\mathrm{H}_{2} \mathrm{O}, 0.01 \mathrm{~g} \mathrm{CoCl}_{2} \times 6 \mathrm{H}_{2} \mathrm{O}, 0.1 \mathrm{~g} \mathrm{MnCl}_{2} \times 4 \mathrm{H}_{2} \mathrm{O}$, and $4.8 \mathrm{mg}$ $\mathrm{Na}_{2} \mathrm{MoO}_{4} \times 2 \mathrm{H}_{2} \mathrm{O}$. The vitamin solution contained per liter of distilled water: $0.5 \mathrm{mg}$ biotin, $0.1 \mathrm{~g}$ vitamin $\mathrm{B}_{1}$, and $0.5 \mathrm{mg}$ vitamin $\mathrm{B}_{12}$. The cultures were incubated at $15^{\circ} \mathrm{C}$ and a light intensity of $\sim 3000$ lux of a cool white fluorescent light ( $16 \mathrm{~h}$ light, 8 h dark).

A recently isolated heterotrophic Pseudomonas str. LFY10 obtained from Prof. Matt Sattley (Indiana Wesleyan University, Marion, IN) was grown on an ammonium-glucose medium and an ammonium-acetate medium. The ammonium-glucose medium contained: 5 g glucose, $0.2 \mathrm{~g} \mathrm{MgSO}_{4} \times 7 \mathrm{H}_{2} \mathrm{O}, 5 \mathrm{~g} \mathrm{NaCl}$, $1.3 \mathrm{~g}\left(\mathrm{NH}_{4}\right)_{2} \mathrm{HPO}_{4}, 1 \mathrm{~g} \mathrm{KH} \mathrm{KO}_{4}, 2 \mathrm{~mL}$ trace element solution SL-4 per liter of distilled water ( $\mathrm{pH} 7.1$ ). The ammonium-acetate medium contained $5 \mathrm{~g} \mathrm{Na}$-acetate, $0.2 \mathrm{~g} \mathrm{MgSO}_{4} \times 7 \mathrm{H}_{2} \mathrm{O}$, $5 \mathrm{~g} \mathrm{NaCl}, 1.3 \mathrm{~g}\left(\mathrm{NH}_{4}\right)_{2} \mathrm{HPO}_{4}, 1 \mathrm{~g} \mathrm{K \textrm {K } _ { 2 }} \mathrm{PO}_{4}, 2 \mathrm{~mL}$ trace element solution SL-4 per liter of distilled water. The $\mathrm{pH}$ was adjusted to 7.1. The cultures were incubated at $25^{\circ} \mathrm{C}$.

After inoculation cell densities, and thereby growth phase, were monitored regularly by flow cytometry (BD Accuri ${ }^{\mathrm{TM}}$ C6, San Jose USA) or by measuring the optical density (OD) at $600 \mathrm{~nm}$ with a spectrometer (Molecular Devices SpectraMax M2, Sunnyvale USA). Culture samples, including water samples for hydrogen isotope analysis, were taken during exponential, stationary and death phase. The water was stored with no headspace in $12 \mathrm{~mL}$ exertainers (Labco) in the dark at $\sim 5^{\circ} \mathrm{C}$ until analysis. Biomass was collected by filtration over a $0.7 \mu \mathrm{m} \mathrm{GF} / \mathrm{F}$ filter (Whatman, GE Healthcare Life Sciences, Little Chalfont, UK) or by centrifugation.

\section{Lipid Extraction}

Bacterial biomass and filters were freeze dried and hydrolyzed directly by base hydrolysis with four volumes of $1 \mathrm{~N} \mathrm{KOH}$ in methanol $(\mathrm{MeOH})$ solution under reflux for $1 \mathrm{~h}$ at $190^{\circ} \mathrm{C}$. Afterwards the $\mathrm{pH}$ was adjusted to 4 with $2 \mathrm{~N} \mathrm{HCl} / \mathrm{MeOH}(1 / 1)$ and the liquid was transferred into a separatory funnel. The residues were further extracted once with $\mathrm{MeOH} / \mathrm{H}_{2} \mathrm{O}(1 / 1)$, twice with $\mathrm{MeOH}$, and three times with dichloromethane (DCM) (two volumes each). The extracts were combined and bidistilled $\mathrm{H}_{2} \mathrm{O}$ (six volumes) was added. The combined solutions were mixed and allowed to separate in a $\mathrm{MeOH} / \mathrm{H}_{2} \mathrm{O}$ and DCM phase, the DCM phase was removed and collected. The $\mathrm{MeOH} / \mathrm{H}_{2} \mathrm{O}$ layer was re-extracted twice with $3 \mathrm{~mL}$ DCM. The combined DCM layers were dried over a $\mathrm{Na}_{2} \mathrm{SO}_{4}$ column and the DCM was evaporated under a stream of nitrogen. The dried extracts were stored at $4^{\circ} \mathrm{C}$ before further workup.

Fatty acids were methylated with a boron trifluoride-methanol solution $\left(\mathrm{BF}_{3}-\mathrm{MeOH}\right)$ for $5 \mathrm{~min}$ at $60^{\circ} \mathrm{C}$. Then $\mathrm{H}_{2} \mathrm{O}$ and DCM were added ( $1 \mathrm{~mL}$ each). The aqueous layer was washed three times with $1 \mathrm{~mL} \mathrm{DCM}$, and the combined DCM fractions were cleaned over a $\mathrm{Na}_{2} \mathrm{SO}_{4}$ column and dried under a stream of nitrogen. In order to obtain a fatty acid fraction, the methylated extract was separated over an aluminum oxide $(\mathrm{AlOx})$ column, eluting the methylated fatty acids with DCM.

In order to identify the position of double bonds in unsaturated fatty acids, the methylated fatty acids were derivatized with dimethyldisulfide (DMDS) (Nichols et al., 1986). Hexane, DMDS and $\mathrm{I}_{2} /$ ether $(60 \mathrm{mg} / \mathrm{mL})$ were added to the fatty acids and incubated at $40^{\circ} \mathrm{C}$ overnight. After adding hexane, the iodine was deactivated by addition of a $5 \%$ aqueous solution of $\mathrm{Na}_{2} \mathrm{~S}_{2} \mathrm{O}_{3}$. The aqueous phase was washed twice with hexane. The combined hexane layers were cleaned over $\mathrm{Na}_{2} \mathrm{SO}_{4}$ column and dried under a stream of nitrogen. The dried extracts were stored at $4^{\circ} \mathrm{C}$ before analysis.

\section{Fatty Acid Analysis}

The fatty acid fractions were analyzed by gas chromatography (GC) using an Agilent 6890 gas chromatograph with a flame ionization detector (FID) using a fused silica capillary column $(25 \mathrm{~m} \times 320 \mu \mathrm{m})$ coated with CP Sil-5 (film thickness $0.12 \mu \mathrm{m}$ ) with helium as carrier gas. The temperature program was the following: initial temperature $70^{\circ} \mathrm{C}$, increase of temperature to $130^{\circ} \mathrm{C}$ with $20^{\circ} \mathrm{C} \mathrm{min}{ }^{-1}$, and then to $320^{\circ} \mathrm{C}$ with $4^{\circ} \mathrm{C} \mathrm{min}{ }^{-1}$ for $10 \mathrm{~min}$. Individual compounds were identified by $\mathrm{GC} / \mathrm{mass}$ spectrometry (GC/MS) using a Agilent 7890A GC instrument and Agilent 5975C VL mass selective detector (MSD).

\section{Hydrogen Isotope Analysis}

Hydrogen isotope analysis of the fatty acids was performed by GC thermal conversion isotope ratio monitoring MS (GC/TC/irMS) using an Agilent 7890 GC connected via Thermo GC Isolink and Conflo IV interfaces to a Thermo Delta V MS according to Chivall et al. (2014). Samples were injected onto an Agilent CP-Sil 5 CB column $(25 \mathrm{~m} \times 0.32 \mathrm{~mm}$ ID; $0.4 \mu \mathrm{m}$ film thickness; $\mathrm{He}$ carrier gas, $\left.1.0 \mathrm{~mL} \mathrm{~min}^{-1}\right)$. The $\mathrm{GC}$ temperature program was 70 to $145^{\circ} \mathrm{C}$ at $20^{\circ} \mathrm{C} \mathrm{min}^{-1}$, then to $200^{\circ} \mathrm{C}$ at $4^{\circ} \mathrm{C} \mathrm{min}{ }^{-1} 320^{\circ} \mathrm{C}$ for $15 \mathrm{~min}$. Eluting compounds were converted to $\mathrm{H}_{2}$ at $1420^{\circ} \mathrm{C}$ in a ceramic tube before introduction to the mass spectrometer. An internal standard, squalane $(\delta \mathrm{D}=-170 \%)$, was co-injected with each fatty acid sample in order to monitor the precision of the measurements. The average $\delta \mathrm{D}$ of the internal standard was $-1.7 \pm 3 \%$. The $\delta \mathrm{D}$ of the individual fatty acids was measured in duplicates and corrected for the added methyl group.

The hydrogen isotopic composition of fatty acids compared to water was expressed as $\varepsilon_{\text {lipid/water }}$ following:

$$
\varepsilon=\left(\frac{1000+\delta \mathrm{D}_{\mathrm{FA}}}{1000+\delta \mathrm{D}_{\text {water }}}-1\right) * 1000
$$

The $\delta \mathrm{D}$ of the water was determined by injecting at least $10 \times 1$ $\mu \mathrm{L}$ on an elemental analysis/thermal conversion/isotope ratio monitoring MS (EA/TC/irMS) using a Thermo Finnigan TC/EA interfaced via a Thermo Finnigan ConFlo III to a Thermo Finnigan Delta ${ }^{+}$XL mass spectrometer following the procedure 
described by M'boule et al. (2014) with North Sea water $(\delta \mathrm{D}=$ $5 \%$ ) and bidistilled water $(\delta \mathrm{D}=-76 \%$ ) as standards.

The $\delta \mathrm{D}$-value of dry sodium acetate was also determined by EA/TC/irMS. NBS 22 mineral oil $(\delta \mathrm{D}=-120.0 \%)$ and polyethylene IAEA-CH-7 $(\delta \mathrm{D}=-100.3 \%)$ were used as standards. The $\delta \mathrm{D}$-value of acetate was measured in triplicate.

The hydrogen isotopic composition of the non-exchangeable hydrogen of the glucose substrate was determined by analyzing the acetylated derivative of glucose. For this, glucose was acetylated using $0.5 \mathrm{~mL}$ acetic anhydride with a pre-determined $\delta \mathrm{D}$-value and $0.5 \mathrm{~mL}$ pyridine for $3 \mathrm{~h}$ at $75^{\circ} \mathrm{C}$. Afterwards, $1 \mathrm{~mL}$ distilled $\mathrm{H}_{2} \mathrm{O}$ was added and the water layer was washed three times with hexane. The hexane was evaporated and the acetylated glucose was dissolved in ethyl acetate and analyzed by GC, GC-MS and GC/TC/irMS similar to the fatty acids. The $\delta \mathrm{D}$-value of the non-exchangeable hydrogen of glucose was calculated by correcting for the added acetyl groups. The acetylated glucose was measured five times.

Statistical analysis was done via One-Way ANOVA test with SigmaPlot Version 12.0 (Systat Software, Inc., San Jose, USA).

\section{Results}

\section{Thiocapsa Roseopersicina}

Thiocapsa roseopersicina was grown photoautotrophically under anoxic conditions with $\mathrm{CO}_{2}$ as sole carbon source and hydrogen sulfide as electron donor. Fatty acids that were present in all growth phases are $\mathrm{C} 16: 1 \omega 7, \mathrm{C} 16: 0$, and $\mathrm{C} 18: 1 \omega 7$. In addition,

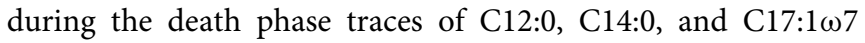
were also detected. The C18:1 fatty acid (30-49\%) was the most abundant fatty acid in all growth phases followed by C16:1 (21-32\%) and C16:0 ( 21\%). Minor fatty acids were C12:0, C14:0, and C17:1 fatty acids with abundances between 7 and $14 \%$ (Table S1). All fatty acids were depleted in D relative to the growth medium (all $\delta \mathrm{D}$-values are summarized in Table S2) and the hydrogen isotopic fractionation expressed as $\varepsilon_{\text {lipid/water }}$ between the fatty acids and the growth water of the individual fatty acids ranged between -153 and $-264 \%$ (Table 1). Fatty acids were most depleted during exponential growth and most enriched during the death phase (Figure 1A, Table 1).

\section{Halochromatium Glycolicum}

Halochromatium glycolicum was grown photoautotrophically, under anoxic conditions with $\mathrm{CO}_{2}$ as sole carbon source and

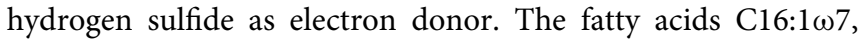

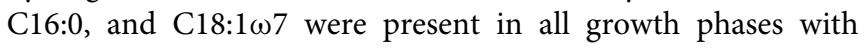
C18:1 fatty acid being the most abundant (52-73\%) and C16:1 the least abundant (7-9\%) (Table S1). In addition, a C19 fatty acid containing a cyclopropane moiety (C19:cyc) was only present in the death phase. All measured fatty acids were depleted in D relative to the growth medium (Table S2) and $\varepsilon_{\text {lipid/water }}$ for the individual fatty acids ranged between -159 and $-230 \%$ (Table 1). The fatty acids were most depleted during exponential growth and most enriched during the death phase (Figure 1B, Table 1). The C16:0 fatty acid was enriched in D by $40-50 \%$ compared to the other fatty acids in all growth phases.

\section{Isochrysis Galbana}

Isochrysis galbana was grown photoautotrophically under oxic conditions with $\mathrm{CO}_{2}$ as sole carbon source (M'boule et al., 2014).

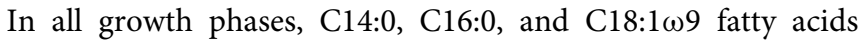
were identified as well as various other unsaturated $\mathrm{C} 18$ and a polyunsaturated C22 fatty acids. Either C14:0 or C18:1 fatty acids are in general the most abundant fatty acids (Table S1). All fatty acids were depleted in D compared to the growth medium (Table S2) and $\varepsilon_{\text {lipid/water-values ranged from }-149 \text { to }-237 \% \text { o }}$ (Table 1). The C14:0 and C16:0 fatty acids were most depleted in $\mathrm{D}$ during exponential growth and became enriched by up to $30 \%$ with increasing age of the culture. On the other hand C18:1 $\omega 9$ fatty acid was most enriched during exponential growth and became depleted in $\mathrm{D}$ with age of the culture by up to $35 \%$ (Figure 1C; Table 1). The D/H ratio of the other unsaturated $\mathrm{C} 18$ and a polyunsaturated C22 fatty acids could not be measured with certainty due to either incomplete separation or low abundance.

\section{Thiobacillus Denitrificans}

Thiobacillus denitrificans was grown chemoautotrophically with

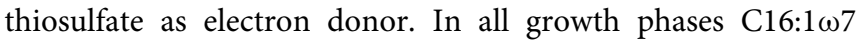
and C16:0 fatty acids were present in equal abundance. Minor amounts of C17:cyc were also detected (Table S1). All fatty acids were depleted in $\mathrm{D}$ relative to the growth medium (Table S2) with $\varepsilon_{\text {lipid/water }}$ of the individual fatty acids ranging between -217 and $-275 \%$ (Table 1). In general, fatty acids were most depleted during exponential growth (Figure 1D). The C16:0 fatty acid was depleted by $10-50 \%$ compared to the other fatty acids in all growth phases.

\section{Pseudomonas str. LFY10}

The Pseudomonas sp. strain was grown heterotrophically on either glucose or acetate as carbon source under oxic conditions. On both substrates, Pseudomonas str. LFY10 produced C16:1 1 7,

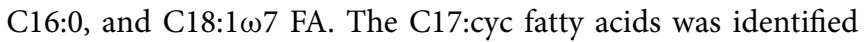
in all growth phases when grown on acetate but only during the death phase when grown on glucose. In the death phase, C19:cyc fatty acid was identified when grown on either substrate (Table S1). There were no differences in fatty acid distribution between exponential and stationary phase with C16:1 and C16:0 being the most abundant fatty acids when grown on glucose and C16:0 being the most abundant fatty acid when grown on acetate (Table S1). In the culture grown on glucose all fatty acids during death phase were enriched in $\mathrm{D}$ relative to the growth medium (Table S2) with $\varepsilon_{\text {lipid/water }}$ ranging between 82 and $197 \%$ (Table 1), as well as to the substrate, with $\varepsilon_{\text {lipid/substrate }}$ ranging between 30 and $161 \%$ (Table 2). All fatty acids became enriched with age of culture (Figure 1D). In the cultures grown on acetate, all fatty acids were significantly enriched compared to both the growth medium and the substrate. The $\varepsilon_{\text {lipid/water-value of the individual fatty acids ranged between } 247}$ and $359 \%$ (Table 1), while the $\varepsilon_{\text {lipid/substrate }}$ of the individual fatty acids was between 351 and 469\% (Table 2). Fatty acids of Pseudomonas str. LFY10 grown on acetate did not show a general enrichment in $\mathrm{D}$ with progressing growth phase (Figure 1F). 
TABLE 1 | D/H fractionation between fatty acids and growth medium for fatty acids produced by different microorganisms under various metabolic conditions.

\begin{tabular}{|c|c|c|c|c|c|c|c|c|c|c|c|c|c|}
\hline \multirow[t]{2}{*}{ Organism } & \multirow[t]{2}{*}{ Substrate } & \multirow{2}{*}{$\begin{array}{c}\delta D_{\text {substrate }} \\
(\% 0)\end{array}$} & \multirow{2}{*}{$\begin{array}{c}\delta D_{\text {water }} \\
(\% 0)\end{array}$} & \multicolumn{8}{|c|}{ Mean $\varepsilon_{\text {lipid/water }}(\% 0)$} & \multirow{2}{*}{$\begin{array}{c}\text { Weighted. } \\
\text { av. }(\% 0)\end{array}$} & \multirow[t]{2}{*}{ GP } \\
\hline & & & & C12:0 & C14:0 & C16:1* & C16:0 & C17:сyc & C17:1 $\varphi$ & C18:1థ & C19:сyc & & \\
\hline Thiocapsa & $\mathrm{CO}_{2}$ & - & $-51 \pm 3$ & & & -264 & -216 & & & -259 & & -252 & $E$ \\
\hline \multirow[t]{2}{*}{ roseopersicina } & light & & $-50 \pm 3$ & & & -260 & -209 & & & -254 & & -247 & $S$ \\
\hline & & & $-59 \pm 3$ & -204 & -209 & -221 & -191 & & -153 & -232 & & -210 & D \\
\hline Halochromatium & $\mathrm{CO}_{2}$ & - & $-50 \pm 2$ & & & -222 & -187 & & & -230 & & -221 & $E$ \\
\hline \multirow[t]{2}{*}{ glycolicum } & light & & $-51 \pm 2$ & & & -225 & -175 & & & -218 & & -210 & S \\
\hline & & & $-61 \pm 2$ & & & -214 & -159 & & & -209 & -187 & -196 & D \\
\hline Isochrysis & $\mathrm{CO}_{2}$ & - & $4 \pm 2$ & & -237 & & -233 & & & -149 & & -225 & $E$ \\
\hline \multirow[t]{2}{*}{ galbana } & light & & $5 \pm 2$ & & -215 & & -205 & & & -179 & & -198 & S \\
\hline & & & $9 \pm 1$ & & -201 & & -200 & & & -184 & & -192 & $\mathrm{D}$ \\
\hline \multirow{3}{*}{$\begin{array}{l}\text { Thiobacillus } \\
\text { denitrificans }\end{array}$} & $\mathrm{CO}_{2}$ & - & $-51 \pm 1$ & & & -262 & -275 & -228 & & & & -265 & $E$ \\
\hline & & & $-49 \pm 3$ & & & -250 & -270 & -229 & & & & -258 & S \\
\hline & & & $-54 \pm 3$ & & & -252 & -270 & -217 & & & & -257 & D \\
\hline \multirow{3}{*}{$\begin{array}{l}\text { Pseudomonas } \\
\text { str. LFY10 }\end{array}$} & glucose & $-8 \pm 11$ & $-56 \pm 2$ & & & 82 & 111 & & & 112 & & 100 & $E$ \\
\hline & & & $-55 \pm 2$ & & & 93 & 123 & & & 124 & & 112 & $S$ \\
\hline & & & $-38 \pm 2$ & & & 123 & 169 & 152 & & 197 & 161 & 164 & D \\
\hline \multirow{3}{*}{$\begin{array}{l}\text { Pseudomonas } \\
\text { str. LFY10 }\end{array}$} & acetate & $-1.8 \pm 3$ & $-57 \pm 2$ & & & 265 & 278 & 359 & & 309 & & 289 & $E$ \\
\hline & & & $-57 \pm 3$ & & & 249 & 261 & 328 & & 290 & & 270 & S \\
\hline & & & $-44 \pm 2$ & & & 247 & 294 & 307 & & 304 & 323 & 300 & D \\
\hline
\end{tabular}

C16:1*, double bond at the $\omega 7$ position; C17:1 $\varphi$, double bond at the $\omega 7$ position; C18:1 $\phi$, double bond in all cultures except for I. galbana ( $\omega 9$ ) at the $\omega 7$ position; GP, growth phase; E, exponential; S, stationary; $D$, death.

\section{Discussion}

\section{Influence of Metabolism on the $\delta d$ of C16:0 Fatty Acid}

The C16:0 fatty acid is the most common and often most abundant fatty acid in bacterial and eukaryotic microorganisms (Gunstone et al., 2012). Indeed, all the cultures tested in this study synthesize at least the C16:0 fatty acid, while other fatty acids were often either absent or present in lower amounts. Therefore, for comparing the hydrogen isotopic fractionation of the different microbes we focus on the C16:0 fatty acid (Figure 2) and discuss the patterns in more detail below. Furthermore, the weighted average of all measured fatty acids for each culture showed the same trend as the C16:0 fatty acid indicating that changes in the hydrogen isotopic composition of individual fatty acids is not strongly affected by the relative abundance of the fatty acids (Table 1, Figure 1).

\section{Photoautotrophs}

The hydrogen isotopic fractionation for the C16:0 fatty acid $\left(\varepsilon_{\mathrm{C} 16: 0 / \text { water }}\right)$ of all photoautotrophs, Thiocapsa roseopersicina, Halochromatium glycolicum, and Isochrysis galbana, is relatively similar and ranged from -187 to $-233 \%$. The oxygenic photoautotroph I. galbana reduce $\mathrm{NADP}^{+}$to NADPH using $\mathrm{H}_{2} \mathrm{O}$ as electron donor (Lengeler et al., 1999) and thus the sole source of hydrogen is water. The $\mathrm{D} / \mathrm{H}$ ratio of fatty acids depends mainly on the fractionation associated with the splitting of water, the reduction of $\mathrm{NADP}^{+}$to $\mathrm{NADPH}$, the transfer of $\mathrm{H}$ to the initial photosynthate and the transfer of $\mathrm{H}$ during fatty acid biosynthesis (Hayes, 2001). The anoxygenic photoautotrophs Thiocapsa roseopersicina and Halochromatium glycolicum both reduce $\mathrm{NADP}^{+}$via reverse electron transport (Imhoff, 2006). Depending on the $\mathrm{pH}, \mathrm{H}_{2} \mathrm{~S}$ is soluble in water and forms $\mathrm{S}^{2-}$ and $2 \mathrm{H}^{+}$with the latter being exchangeable with the protons of water. Since the amount of $\mathrm{H}_{2} \mathrm{~S}$ is relatively small compared to water $(0.04 \%)$, the $\mathrm{D} / \mathrm{H}$ ratio of water will not be substantially affected. The similar fractionation of anoxygenic and oxygenic photoautotrophs suggest that the steps leading to the production of NADPH under both conditions have similar fractionation factors. The same has been observed for various other algae and an anoxygenic, photoautotrophic bacterium (Zhang and Sachs, 2007; Zhang et al., 2009a).

\section{Chemolithoautotrophs}

The C16:0 fatty acid of the chemolithoautotrophic T. denitrificans is more depleted in D compared to those of the photoautotrophs (Figure 2) even though water is also the most likely source for hydrogen here. $T$. denitrificans contains an electron transport chain to reduce $\mathrm{NAD}^{+}$to $\mathrm{NADH}$ by quinonecytochrome b (Beller et al., 2006). The electron transport 


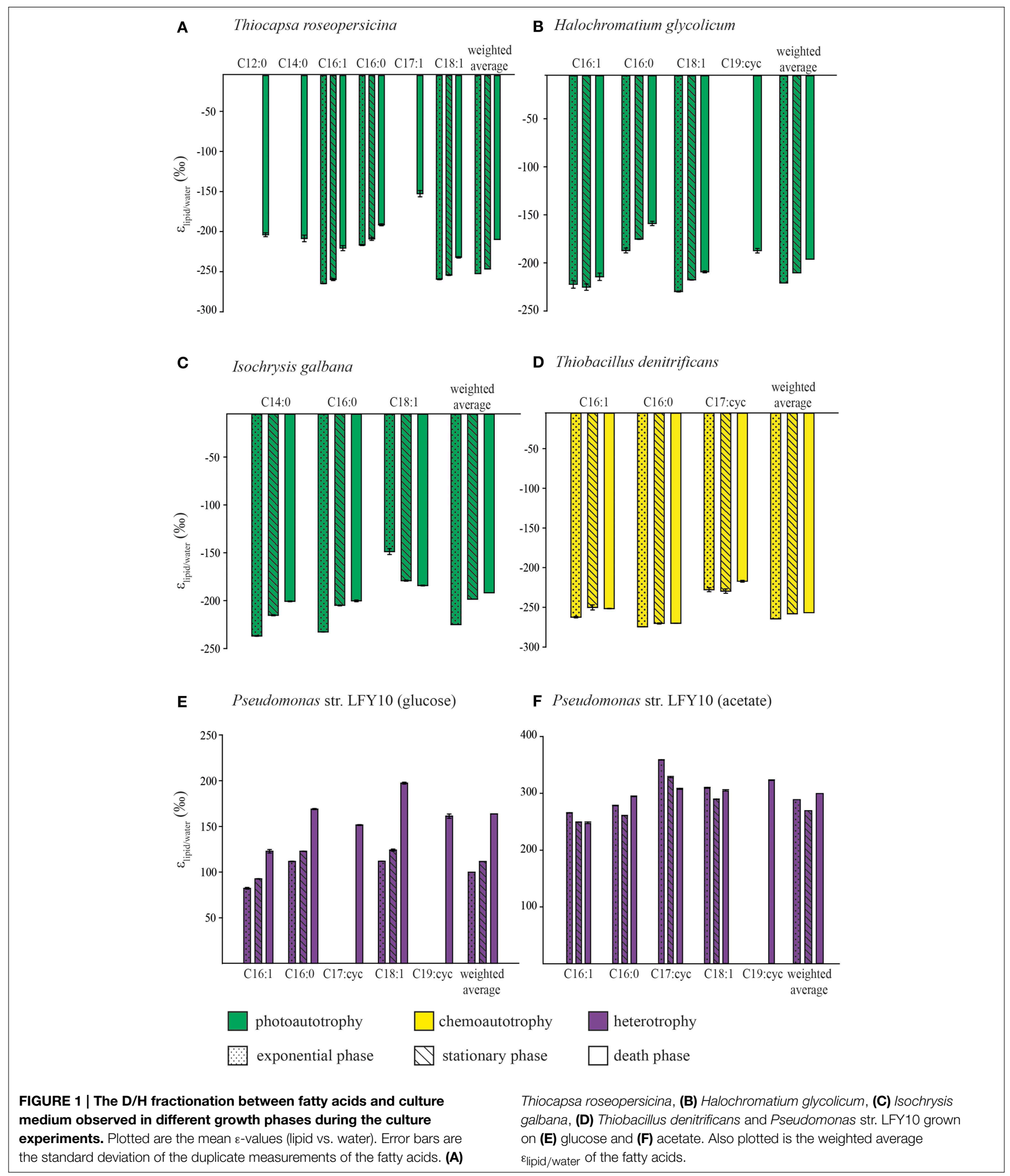

chain, the enzymes involved and the substrate reduced are different from photoautotrophic microorganisms, which could potentially explain the negative offset in fatty acid $\mathrm{D} / \mathrm{H}$ ratios.
Another possibility could be that $T$. denitrificans might, like T. thioparus to which it is physiologically similar (Kelly and Wood, 2000), rather use NADH than NADPH as hydrogen 
TABLE 2 | D/H fractionation between fatty acids and growth substrate for fatty acids produced by Pseudomonas str. LFY10.

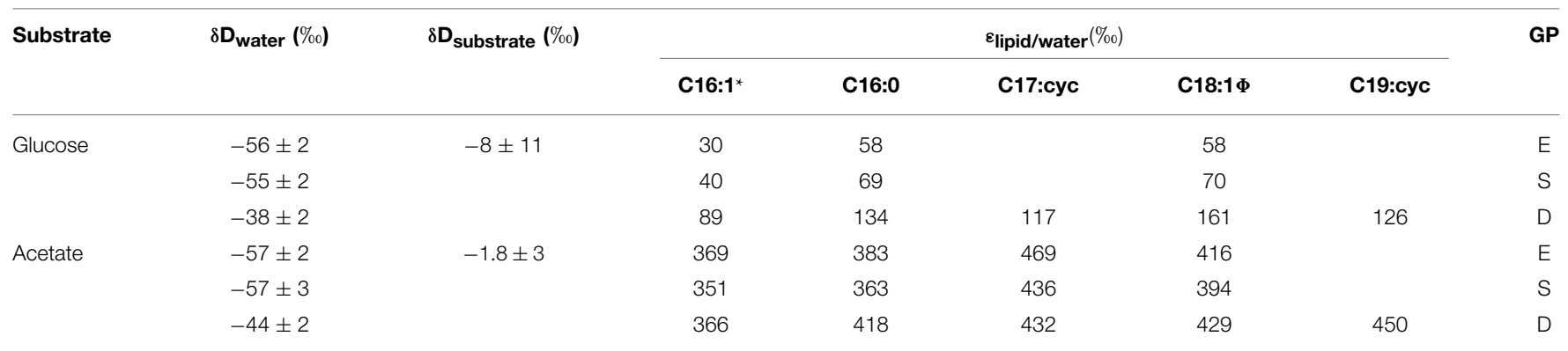

C16: $1^{*}$, double bond at the $\omega 7$ position; C18:1 $\phi$, double bond at the $\omega 7$ position. GP, growth phase; E, exponential, S, stationary, D, death.

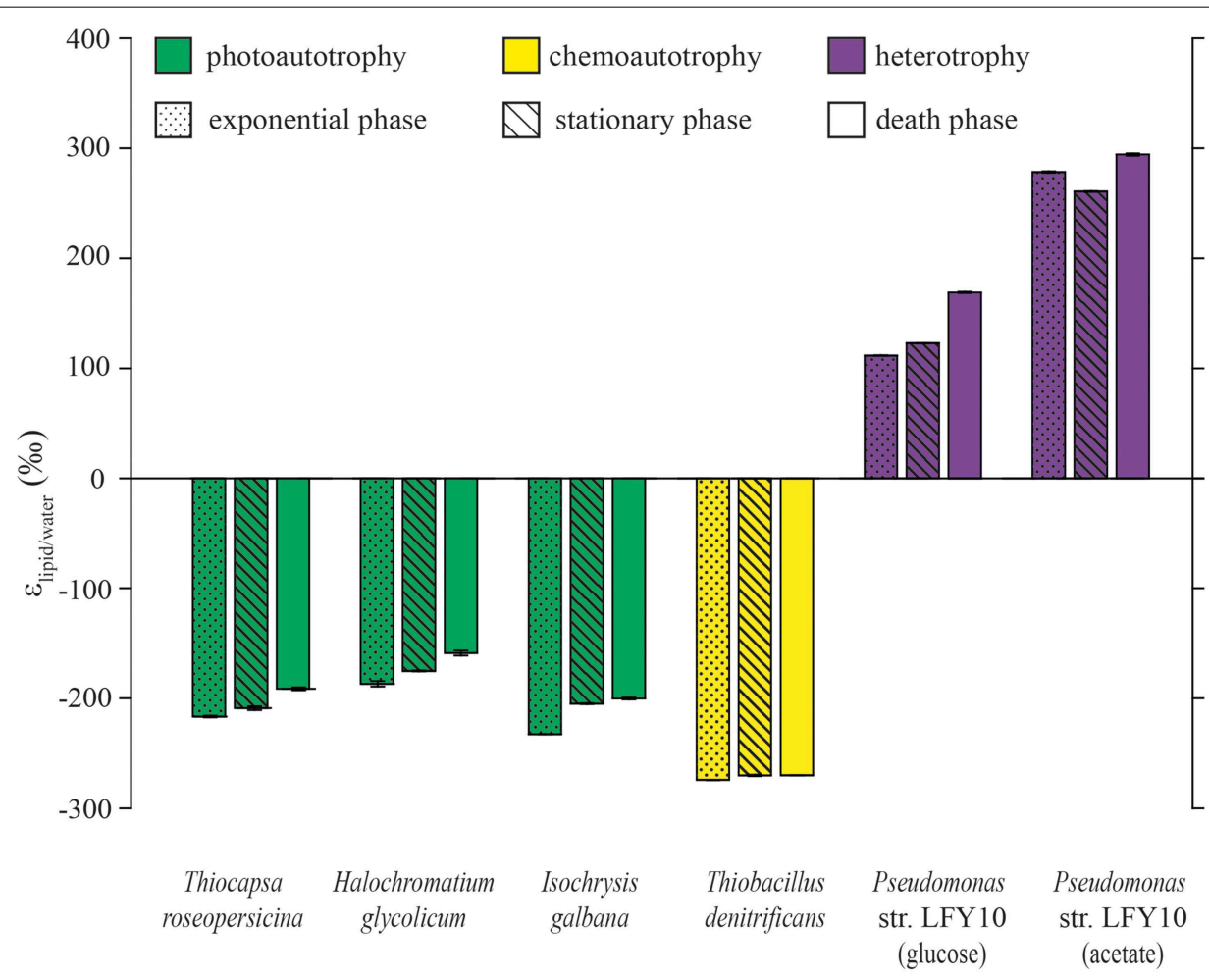

FIGURE 2 | Impact of growth phase (exponential, stationary and death phase) on the hydrogen isotopic fractionation of the C16:0 fatty acid of the different cultivated microbes. Plotted are the mean $\varepsilon$-values of the duplicate measurements of the fatty acids and error bars are the standard deviation of the duplicate measurements of the fatty acids. Cultures are Thiocapsa roseopersicina, Halochromatium glycolicum, Isochrysis galbana, Thiobacillus denitrificans and Pseudomonas str. LFY10 grown on glucose and acetate. source during fatty acid biosynthesis. Matin and Rittenberg (1971) also suggested that in obligate chemolithoautotrophic Thiobacilli NADH, and not NADPH, is used for reducing power during biosynthesis. Additionally, at least some heterotrophs have been shown to contain a NADH-NADPH converting transhydrogenase. In case of excess NADPH the enzyme leads to reduction of $\mathrm{NAD}^{+}$to $\mathrm{NADH}$ while oxidizing $\mathrm{NADPH}$ to $\mathrm{NADP}^{+}$. This would leave the remaining NADPH pool enriched and the NADH strongly depleted in D (Zhang et al., 2009a). This could be an additional fractionation effect that potentially contributes to the relatively depleted fatty acids in chemoautotrophs which use NADH. However, the genome of
Thiobacillus denitrificans does not contain a NADH-NADPH converting transhydrogenase (Beller et al., 2006), although we cannot exclude the possibility it contains enzymes with a similar function.

\section{Heterotrophs}

The heterotroph Pseudomonas str. LFY10 produces D-enriched fatty acids compared to D-depleted fatty acids in all autotrophs. Furthermore, similar to Escherichia coli (Zhang et al., 2009a), $\varepsilon_{\text {lipid/water }}$ of the individual fatty acids of Pseudomonas str. LFY10 is higher, when grown on acetate than on glucose. In heterotrophic organisms an important hydrogen source is 
the organic substrate used as carbon and energy source. All Pseudomonas species possess the tricarboxylic acid (TCA) cycle, the pentose phosphate pathway (Moore et al., 2006) and possibly also a NADH-NADPH converting transhydrogenase (Louie and Kaplan, 1970; French et al., 1997). The observed enrichment in $\mathrm{D}$ is suggested to occur during $\mathrm{NADP}^{+}$reduction in the TCA cycle or due to conversion of excess NADPH to NADH via the NADH-NADPH converting transhydrogenase (Zhang et al., 2009a). Some of the supplied acetate might also be used as a direct building block during fatty acid biosynthesis and therefore some of the $\mathrm{H}$ of fatty acids would come directly from acetate. When Pseudomonas sp. is grown on glucose, $\mathrm{NADP}^{+}$will be reduced in the pentose phosphate pathway in addition to the TCA cycle. While $\mathrm{NADP}^{+}$reduction in the TCA cycle leads to NADPH enriched in D, the reduction in the pentose phosphate pathway might lead to more depleted NADPH. The mixed NADPH pool could thus explain why the fatty acids produced by Pseudomonas str. LFY10 are less enriched in $\mathrm{D}$ when grown on glucose compared to acetate.

\section{Influence of Growth Phase on the $\delta \mathrm{d}$ of Fatty Acids}

In addition to metabolism we investigated the effect of growth phase. Fatty acids produced by the different microorganisms are in general, but not exclusively, increasingly enriched in D with increasing age of the culture. From exponential to stationary phase, the $\varepsilon_{\text {lipid/water-values of the C16:0 fatty acids of all but }}$ one culture increase by around 10\%. Only for Pseudomonas str. LFY10 grown on acetate a depletion of $15 \%$ was observed (Figure 2).

Few studies have focused on the impact of growth phase on $\mathrm{D} / \mathrm{H}$ ratios of lipids. Interestingly, Wolhowe et al. (2009) and Chivall et al. (2014) showed that alkenones produced by haptophyte algae are more depleted in $\mathrm{D}$ in stationary growth phase compared to exponential growth phase, which is in contrast to the enrichment observed here for the C16:0 fatty acid as well as the weighted average of fatty acids in $I$. galbana (Figure 1C). This is interesting considering that the C16:0 fatty acid is assumed to serve as a precursor for the synthesis of alkenones (Rontani et al., 2006; Wallace, 2012). A possible explanation is that the C16:0 is produced mainly in the chloroplast, while it is assumed that the alkenones are produced in the cytosol by chain elongation (Wallace, 2012). Therefore, two different NADPH pools could be used for the biosynthesis of alkenones and C16:0 fatty acid, respectively. The observed isotopic difference with growth phase could be due to a decrease in structural lipid synthesis such as fatty acids since the algae are no longer growing and dividing as a result of nutrient limitation. At the same time NADPH is still produced during photosynthesis leading to a surplus of reducing power. This excess NADPH will then be used for the production of storage products, such as alkenones, which do not contain limiting elements like $\mathrm{N}$ or $\mathrm{P}$ (Wolhowe et al., 2009). Alternatively, when a smaller fraction of the relatively D depleted fatty acids are used for structural components such as membranes, they may be used for alkenone biosynthesis resulting in more $\mathrm{D}$ depleted alkenones with growth phase.

Zhang et al. (2009a) already reported that heterotrophic microorganisms like Cupriavidus necator and C. oxalaticus produce fatty acids during exponential growth that are more enriched in D compared to fatty acids produced during stationary phase ( $\varepsilon_{\text {lipid/water }} 169$ vs. $70 \%$ and 149 vs. $95 \%$, respectively) when grown on succinate. Like acetate, succinate is metabolized via the TCA cycle which may thus lead to production of $\mathrm{NADPH}$ enriched in D. Thus, for heterotrophs, growth on substrates that are directly involved in the TCA cycle apparently leads to a depletion in $\mathrm{D}$ of all fatty acids, including C16:0, when shifting from exponential to stationary phase. In contrast, growth on substrates that are involved in the pentose phosphate pathway, like glucose, apparently leads to enrichment in $\mathrm{D}$ of fatty acids in stationary phase compared to exponential phase.

Although growth phase changes result in changes in $\mathrm{D} / \mathrm{H}$ ratios of fatty acids these are relatively minor compared to the impact of metabolism on fatty acid $\mathrm{D} / \mathrm{H}$ ratios. Therefore, changes in growth phase in microbial communities in the environment can be considered to have relatively minor impact on the overall isotopic signal of the fatty acid pool of the whole community. Additionally, lipid identity does not play a major role on the hydrogen isotopic composition of fatty acids compared to metabolism. The $\varepsilon_{\text {lipid/water-values of the different }}$ fatty acids with the same initial biosynthetic pathways fall in a similar range and differences observed are due to the addition and/or removal of hydrogen atoms related with chain length and degree of unsaturation.

\section{Application of $\delta \mathbf{d}$ of Fatty Acids as a Population Metabolism Indicator}

When we summarize all published (including this study) $\varepsilon_{\mathrm{C} 16: 0 / \text { water-values of different microorganisms grown as either }}$ photoautotroph, chemoautotroph or heterotroph (Sessions et al., 1999, 2002; Chikaraishi et al., 2004; Valentine et al., 2004; Zhang and Sachs, 2007; Campbell et al., 2009; Zhang et al., 2009a; Dirghangi and Pagani, 2013; Fang et al., 2014), the three metabolism types show distinct, but slightly overlapping ranges (Figure 3). Microorganisms grown as photoautotrophs produce fatty acids which are depleted in $\mathrm{D}$ relative to the growth medium with the majority of $\varepsilon_{\mathrm{C} 16: 0 / \text { water-values ranging around }-170}$ to $-200 \%$. The only exceptions are the cultures of the freshwater algae Eudorina unicocca and Volvox aureus which produce Denriched fatty acids compared to other photoautotrophs (Zhang and Sachs, 2007). A possible explanation could be that both Eudorina unicocca and Volvox aureus are colony forming algae which, unlike the colony forming algae Botryococcus braunii (Zhang and Sachs, 2007), consist of two different cell types, somatic cells and reproductive (gonidia) cells (Herron et al., 2009). Possible differences in the metabolism between these two different cell types could play a role in the relatively enrichment in D of the C16:0 fatty acid compared to other photoautotrophs. Due to the fact that the $\varepsilon_{\text {lipid/water-values of }}$ these two organisms do not seem to follow the pattern observed for the $\mathrm{C} 16: 0$ fatty acids produced by all photoautotrophs we have 


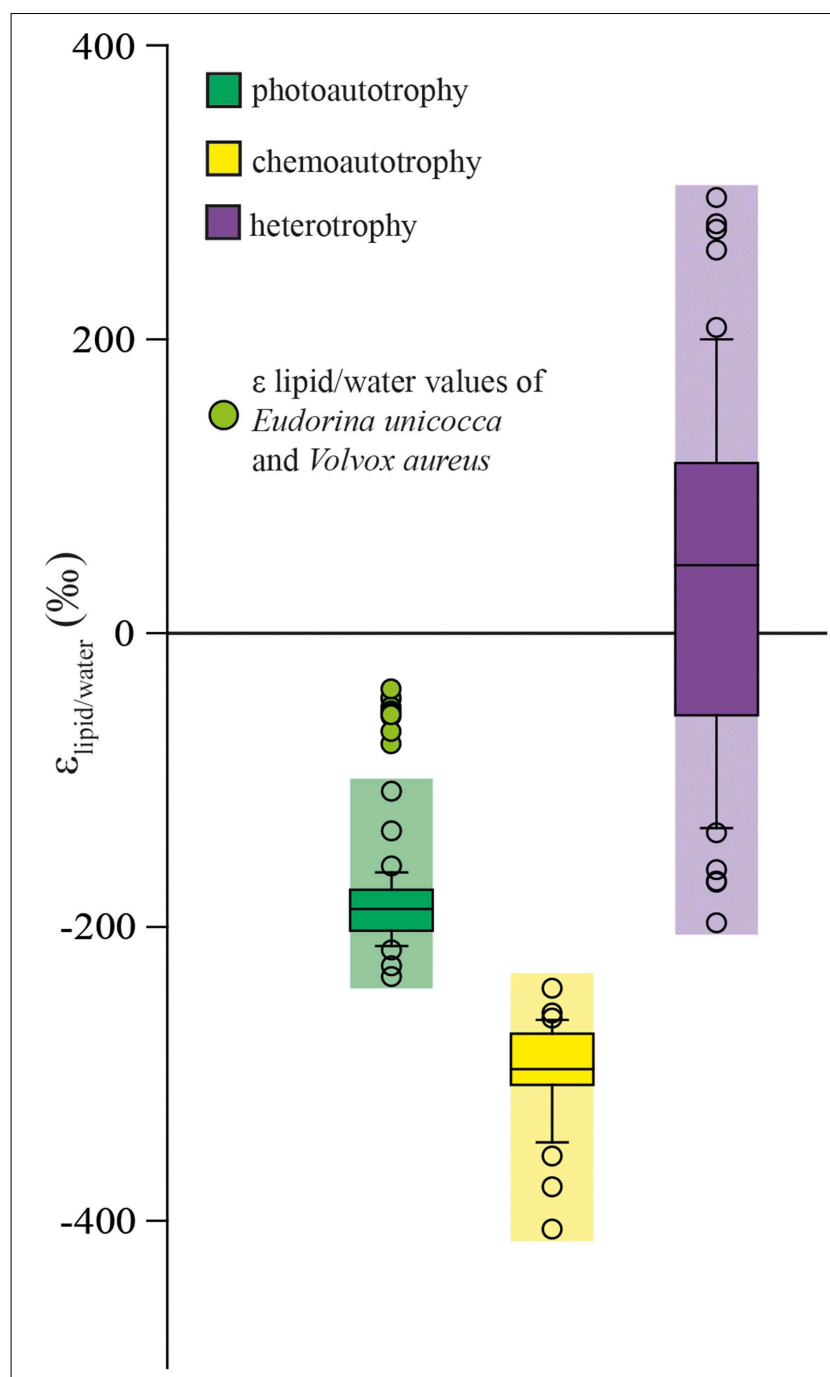

FIGURE 3 | Box plots of D/H fractionations between the C16:0 fatty acid and culture medium observed in different culture experiments. Cultures included from this study are Thiocapsa roseopersicina,

Halochromatium glycolicum, Isochrysis galbana, Thiobacillus denitrificans, and Pseudomonas str. LFY10. Additionally, published data for Isochrysis galbana, Ascophyllum sp., Alexandrium fundyense, Methylococcus capsulatus, Saragassum filicinum, Undararia pinnatifida, Binghamia californica, Gelidium japonica, Sporomusa sp., Botrycoccus braunii, Eudorina unicocca, Volvox aureus, Desulfobacterium autotrophicum, Cupriavidus oxalaticus, Cupriavidus necator, Escherichia coli, Rhodopseudomonas palustris, Tetrahymena

thermophile, and Moritella japonica DSK 1 have been included (Sessions et al., 1999, 2002; Chikaraishi et al., 2004; Valentine et al., 2004; Zhang and Sachs, 2007; Campbell et al., 2009; Zhang et al., 2009a; Dirghangi and Pagani, 2013; Fang et al., 2014).

indicated them separately in our summary in Figure 3. Thus, C16:0 fatty acid of photoautotrophs have a mean $\varepsilon_{\mathrm{C} 16: 0 / \text { water }^{-}}$ value of $-186 \%$ and range between -162 and $-215 \%$ ( $95 \%$ confidence interval, $n=34$ ). Chemoautotrophically grown microorganisms produce fatty acids with a mean $\varepsilon_{\mathrm{C} 16: 0 / \text { water }^{-}}$ value of $-298 \%$ and ranging between -264 and $-345 \%$ (95\% confidence interval, $n=32$ ) which is depleted by ca. $100 \%$ relative to fatty acids produced by photoautotrophs.
Heterotrophically grown microorganisms typically show an enrichment in $\mathrm{D}$ of the lipids relative to the water (with a

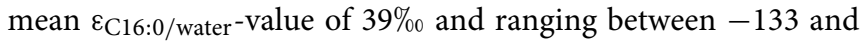
$199 \%$ ( $95 \%$ confidence interval, $n=53$ ). The differences between the different metabolisms are significant $(P<0.001)$ and should allow for the characterization of the dominant metabolism of microbial communities in the environment by analyzing the isotopic difference between C16:0 fatty acid and water. However, several issues should be kept in mind. Relatively few microorganisms have been analyzed for their fatty acid hydrogen isotopic composition, and although most of them fit the general pattern it is possible that exceptions to this pattern arise once other microorganisms are analyzed in the future. In the environment all microorganisms producing the C16:0 fatty acid will contribute to the fatty acid pool in varying amounts depending on the amount produced in the cell. Therefore, the $\varepsilon_{\mathrm{C} 16: 0 / \text { water-value in an environmental sample will not so much }}$ represent the average $\varepsilon_{\text {lipid/water-value of the whole microbial }}$ community but will also be affected by the relative abundance of the C16:0 fatty acid in the various contributing microbes. For instance, the pink streamer (PS) communities in Yellowstone National Park are dominated by chemoautotrophic Aquificales which mainly produce C20:1, C21:cyc with C18:0 and C16:0 fatty acids occurring only in minor amounts, while C16:0 fatty acid is abundant in members of the co-occurring genus Thermus which are heterotrophic. Thus, the $\mathrm{D} / \mathrm{H}$ ratio of the $\mathrm{C} 16: 0$ fatty acid reflects heterotrophy rather than chemoautotrophy in these PS communities despite the dominance of chemoautotrophs (Osburn et al., 2011).

Nevertheless, in order to obtain an idea of the dominating metabolism of a microbial community in the present, as well

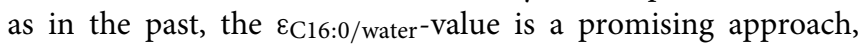
possibly combined with the $\varepsilon_{\text {lipid/water-value of other fatty }}$ acids and potentially biomarker lipids with a more restricted origin.

\section{Conclusion}

The hydrogen isotopic composition of fatty acids produced by a range of different microorganisms depends on the general metabolism expressed during growth. Both photoautotrophs and chemoautotrophs produce fatty acids strongly depleted in D, while heterotrophs produce fatty acids enriched in D compared to the growth medium. Fatty acids produced during different growth phases become somewhat enriched in $\mathrm{D}$ with increasing age of the culture in most of the experiments described here. Thus, growth phase likely plays a minor role in controlling the $\mathrm{D} / \mathrm{H}$ ratio of fatty acids relative to metabolism in the natural environment. Our results suggest that an overall characterization of community metabolism via the $\mathrm{D} / \mathrm{H}$ ratio of fatty acids is potentially feasible.

\section{Acknowledgments}

We thank three reviewers and the editor Prof. James Cotner for their constructive comments. The authors would like to thank D. Chivall and D. M'Boule (NIOZ BGC) for providing the 
different Isochrysis galbana cultures, A. Noordeloos and C. van Sloten (NIOZ BIO) for help with using the Accuri and M. Verweij (NIOZ BGC) for help with the GC-MS measurements. MvdM was funded by the Dutch Organisation for Scientific Research (NWO) through a VIDI grant.

\section{References}

Agrawal, A., and Lal, B. (2009). Rapid detection and quantification of bisulfite reductase genes in oil field samples using real-time PCR. FEMS Microbiol. Ecol. 69, 301-312. doi: 10.1111/j.1574-6941.2009.00714.x

Akerman, N. H., Butterfield, D. A., and Huber, J. A. (2013). Phylogenetic diversity and functional gene patterns of sulfur-oxidizing subseafloor Epsilonproteobacteria in diffuse hydrothermal vent fluids. Front. Microbiol. 4:185. doi: $10.3389 /$ fmicb. 2013.00185

Amann, R. I., Ludwig, W., and Schleifer, K. H. (1995). Phylogenetic identification and in situ detection of individual microbial cells without cultivation. Microbiol. Mol. Biol. Rev. 59, 143-169.

Arrigo, K. R. (2005). Marine microorganisms and global nutrient cycles. Nature 437, 349-355. doi: 10.1038/nature04159

Beller, H. R., Chain, P. S. G., Letain, T. E., Chakicherla, A., Larimer, F. W., Richardson, P. M., et al. (2006). The genome sequence of the obligately chemolithoautotrophic, facultatively anaerobic bacterium Thiobacillus denitrificans. J. Bacteriol. 188, 1473-1488. doi: 10.1128/jb.188.4.1473-1488.2006

Blazejak, A., and Schippers, A. (2011). Real-Time PCR quantification and diversity analysis of the functional genes aprA and $d s r A$ of sulfate-reducing prokaryotes in marine sediments of the Peru Continental Margin and the Black Sea. Front. Microbiol. 2:253. doi: 10.3389/fmicb.2011.00253

Boschker, H. T. S., Nold, S. C., Wellsbury, P., Bos, D., de Graaf, W., Pel, R., et al. (1998). Direct linking of microbial populations to specific biogeochemical processes by ${ }^{13} \mathrm{C}$-labelling of biomarkers. Nature $392,801-805$. doi: $10.1038 / 33900$

Bowen, J. L., Babbin, A. R., Kearns, P. J., and Ward, B. B. (2014). Connecting the dots: linking nitrogen cycle gene expression to nitrogen fluxes in marine sediment mesocosms. Front. Microbiol. 5:429. doi: 10.3389/fmicb.2014.00429

Campbell, B. J., Li, C., Sessions, A. L., and Valentine, D. L. (2009). Hydrogen isotopic fractionation in lipid biosynthesis by $\mathrm{H}_{2}$-consuming Desulfobacterium autotrophicum. Geochim. Cosmochim. Acta 73, 2744-2757. doi: 10.1016/j.gca.2009.02.034

Cebron, A., Bodrossy, L., Stralis-Pavese, N., Singer, A. C., Thompson, I. P., Prosser, J. I., et al. (2007). Nutrient amendments in soil DNA stable isotope probing experiments reduce the observed methanotroph diversity. Appl. Environ. Microbiol. 73, 798-807. doi: 10.1128/aem.01491-06

Chapelle, F. H., and Lovley, D. R. (1990). Rates of microbial metabolism in deep coastal plain aquifers. Appl. Environ. Microbiol. 56, 1865-1874.

Chikaraishi, Y., Suzuki, Y., and Naraoka, H. (2004). Hydrogen isotopic fractionations during desaturation and elongation associated with polyunsaturated fatty acid biosynthesis in marine macroalgae. Phytochemistry 65, 2293-2300. doi: 10.1016/j.phytochem.2004.06.030

Chivall, D., M'boule, D., Sinke-Schoen, D., Sinninghe Damsté, J. S., Schouten, S., and van der Meer, M. T. J. (2014). The effects of growth phase and salinity on the hydrogen isotopic composition of alkenones produced by coastal haptophyte algae. Geochim. Cosmochim. Acta 140, 381-390. doi: 10.1016/j.gca.2014.05.043

Conrad, R. (1996). Soil microorganisms as controllers of atmospheric trace gases $\left(\mathrm{H}_{2}, \mathrm{CO}, \mathrm{CH}_{4}, \mathrm{OCS}, \mathrm{N}_{2} \mathrm{O}\right.$, and NO). Microbiol. Rev. 60, 609-640.

Corredor, J. E., Wawrik, B., Paul, J. H., Tran, H., Kerkhof, L., Lopez, J. M., et al. (2004). Geochemical rate-RNA integrated study: ribulose-1,5-bisphosphate carboxylase/oxygenase gene transcription and photosynthetic capacity of planktonic photoautotrophs. Appl. Environ. Microbiol. 70, 5459-5468. doi: 10.1128/aem.70.9.5459-5468.2004

Dirghangi, S. S., and Pagani, M. (2013). Hydrogen isotope fractionation during lipid biosynthesis by Tetrahymena thermophila. Org. Geochem. 64, 105-111. doi: 10.1016/j.orggeochem.2013.09.007

\section{Supplementary Material}

The Supplementary Material for this article can be found online at: http://journal.frontiersin.org/article/10.3389/fmicb. 2015.00408/abstract

Dumont, M. G., and Murrell, J. C. (2005). Stable isotope probing - linking microbial identity to function. Nat. Rev. Microbiol. 3, 499-504. doi: 10.1038/nrmicro1162

Falkowski, P. G., and Godfrey, L. V. (2008). Electrons, life and the evolution of Earth's oxygen cycle. Philos. Trans. R. Soc. B Biol. Sci. 363, 2705-2716. doi: 10.1098/rstb.2008.0054

Fang, J., Li, C., Zhang, L., Davis, T., Kato, C., and Bartlett, D. H. (2014). Hydrogen isotope fractionation in lipid biosynthesis by the piezophilic bacterium Moritella japonica DSK1. Chem. Geol. 367, 34-38. doi: 10.1016/j.chemgeo.2013.12.018

French, C. E., Boonstra, B., Bufton, K. A., and Bruce, N.C. (1997). Cloning, sequence, and properties of the soluble pyridine nucleotide transhydrogenase of Pseudomonas fluorescens. J. Bacteriol. 179, 2761-2765.

Guillard, R. R. L. (1975). "Culture of phytoplakton for feeding marine invertebrates," in Culture of Marine Invertebrate Animals, eds W. L. Smith and M. H. Chanley (New York, NY: Plenum Press; Springer), 26-60.

Gunstone, F. D., Harwood, J. L., and Dijkstra, A. J. (2012). The Lipid Handbook with CD-ROM. Boca Raton, FL: CRC Press.

Hayes, J. M. (2001). Fractionation of carbon and hydrogen isotopes in biosynthetic processes. Rev. Mineral. Geochem. 43, 225-277. doi: 10.2138/gsrmg.43.1.225

Henry, S., Baudoin, E., Lopez-Gutierrez, J. C., Martin-Laurent, F., Brauman, A., and Philippot, L. (2004). Quantification of denitrifying bacteria in soils by nirK gene targeted real-time PCR. J. Microbiol. Methods 59, 327-335. doi: 10.1016/j.mimet.2004.07.002

Herron, M. D., Hackett, J. D., Aylward, F. O., and Michod, R. E. (2009). Triassic origin and early radiation of multicellular volvocine algae. Proc. Natl. Acad. Sci. U.S.A. 106, 3254-3258. doi: 10.1073/pnas.0811205106

Holmes, D. E., Nevin, K. P., O’neil, R. A., Ward, J. E., Adams, L. A., Woodard, T. L., et al. (2005). Potential for quantifying expression of the Geobacteraceae citrate synthase gene to assess the activity of Geobacteraceae in the subsurface and on current-harvesting electrodes. Appl. Environ. Microbiol. 71, 6870-6877. doi: 10.1128/aem.71.11.6870-6877.2005

Hügler, M., and Sievert, S. M. (2011). Beyond the calvin cycle: autotrophic carbon fixation in the ocean. Ann. Rev. Mar. Sci. 3, 261-289. doi: 10.1146/annurevmarine-120709-142712

Imhoff, J. (2006). “The chromatiaceae," in The Prokaryotes, eds M. Dworkin, S. Falkow, E. Rosenberg, K.-H. Schleifer, and E. Stackebrandt (New York, NY: Springer), 846-873.

Jensen, S., Neufeld, J. D., Birkeland, N.-K., Hovland, M., and Murrell, J. C. (2008) Insight into the microbial community structure of a Norwegian deep-water coral reef environment. Deep Sea Res. I Oceanogr. Res. Pap. 55, 1554-1563. doi: 10.1016/j.dsr.2008.06.008

Kelly, D. P., and Wood, A. P. (2000). Confirmation of Thiobacillus denitrificans as a species of the genus Thiobacillus, in the b-subclass of the Proteobacteria, with strain NCIMB 9548 as the type strain. Int. J. Syst. Evol. Microbiol. 50, 547-550. doi: 10.1099/00207713-50-2-547

Kong, W., Ream, D. C., Priscu, J. C., and Morgan-Kiss, R. M. (2012). Diversity and expression of RubisCO genes in a perennially ice-covered Antarctic lake during the polar night transition. Appl. Environ. Microbiol. 78, 4358-4366. doi: 10.1128/aem.00029-12

Lengeler, J. W., Drews, G., and Schlegel, H. G. (1999). Biology of the Prokaryotes. New York, NY: Thieme.

Louie, D. D., and Kaplan, N. O. (1970). Stereospecificity of hydrogen transfer reactions of Pseudomonas aeruginosa pyridine nucleotide transhydrogenase. J. Biol. Chem. 245, 5691-5698.

M'boule, D., Chivall, D., Sinke-Schoen, D., Sinninghe Damsté, J. S., Schouten, S., and Van der Meer, M. T. J. (2014). Salinity dependent hydrogen isotope 
fractionation in alkenones produced by coastal and open ocean haptophyte algae. Geochim. Cosmochim. Acta 130, 126-135. doi: 10.1016/j.gca.2014.01.029

Manefield, M., Whiteley, A. S., Griffiths, R. I., and Bailey, M. J. (2002). RNA stable isotope probing, a novel means of linking microbial community function to phylogeny. Appl. Environ. Microbiol. 68, 5367-5373. doi: 10.1128/aem.68.11.5367-5373.2002

Matin, A., and Rittenberg, S. C. (1971). Enzymes of carbohydrate metabolism in Thiobacillus species. J. Bacteriol. 107, 179-186.

Moore, E. R., Tindall, B. J., Martins Dos Santos, V. A., Pieper, D. H., Ramos, J.L., and Palleroni, N. J. (2006). "Nonmedical: Pseudomonas," in The Prokaryotes, eds M. Dworkin, S. Falkow, E. Rosenberg, K.-H. Schleifer, and E. Stackebrandt (New York, NY: Springer), 646-703.

Morel, F. M. M., and Price, N. M. (2003). The biogeochemical cycles of trace metals in the oceans. Science 300, 944-947. doi: 10.1126/science.1083545

Muyzer, G., and Stams, A. J. M. (2008). The ecology and biotechnology of sulphatereducing bacteria. Nat. Rev. Microbiol. 6, 441-454. doi: 10.1038/nrmicro1892

Neufeld, J. D., Wagner, M., and Murrell, J. C. (2007). Who eats what, where and when? Isotope-labelling experiments are coming of age. ISME J. 1, 103-110. doi: 10.1038/ismej.2007.30

Nichols, P. D., Guckert, J. B., and White, D. C. (1986). Determination of monosaturated fatty acid double-bond position and geometry for microbial monocultures and complex consortia by capillary GC-MS of their dimethyl disulphide adducts. J. Microbiol. Methods 5, 49-55. doi: 10.1016/01677012(86)90023-0

Nold, S. C., and Ward, D. M. (1996). Photosynthate partitioning and fermentation in hot spring microbial mat communities. Appl. Environ. Microbiol. 62, 4598-4607.

Orcutt, B. N., Sylvan, J. B., Knab, N. J., and Edwards, K. J. (2011). Microbial ecology of the dark ocean above, at, and below the seafloor. Microbiol. Mol. Biol. Rev. 75, 361-422. doi: $10.1128 / \mathrm{mmbr} .00039-10$

Osburn, M. R., Sessions, A. L., Pepe-Ranney, C., and Spear, J. R. (2011). Hydrogen-isotopic variability in fatty acids from Yellowstone National Park hot spring microbial communities. Geochim. Cosmochim. Acta 75, 4830-4845. doi: 10.1016/j.gca.2011.05.038

Overmann, J. (2006). "Principles of enrichment, isolation, cultivation and preservation of prokaryotes," in The Prokaryotes, eds E. Rosenberg, E. F. DeLong, S. Lory, E. Stackebrandt, and F. Thompson (New York, NY: Springer), $80-136$.

Pfennig, N. (1965). Anreicherungskulturen für rote und grüne Schwefelbakterien. Zentralbl. Bakteriol. Parasitenkd. Infektionskrankh. Hyg. Abt. 1(Suppl. 1), 179-189; 503-505.

Phelps, T. J., Murphy, E. M., Pfiffner, S. M., and White, D. C. (1994). Comparison between geochemical and biological estimates of subsurface microbial activities. Microb. Ecol. 28, 335-349. doi: 10.1007/bf00662027

Radajewski, S., Ineson, P., Parekh, N. R., and Murrell, J. C. (2000). Stableisotope probing as a tool in microbial ecology. Nature 403, 646-649. doi: $10.1038 / 35001054$

Radajewski, S., McDonald, I. R., and Murrell, J. C. (2003). Stable-isotope probing of nucleic acids: a window to the function of uncultured microorganisms. Curr. Opin. Biotechnol. 14, 296-302. doi: 10.1016/s0958-1669(03)00064-8

Robins, R. J., Billault, I., Duan, J.-R., Guiet, S., Pionnier, S., and Zhang, B.-L. (2003). Measurement of ${ }^{2} \mathrm{H}$ distribution in natural products by quantitative ${ }^{2} \mathrm{H}$ NMR: an approach to understanding metabolism and enzyme mechanism. Phytochem. Rev. 2, 87-102. doi: 10.1023/B:PHYT.0000004301.52646.a8

Rontani, J. F., Prahl, F. G., and Volkman, J. K. (2006). Re-examination of the double bond positions in alkenones and derivatives: biosynthetic implications. J. Phycol. 42, 800-813. doi: 10.1111/j.1529-8817.2006.00251.x

Saito, K., Kawaguchi, A., Okuda, S., Seyama, Y., and Yamakawa, T. (1980). Incorporation of hydrogen atoms from deuterated water and stereospecifically deuterium labeled nicotinamide nucleotides into fatty acids with the Escherichia coli fatty acid synthetase system. Biochim. Biophys. Acta 618, 202-213.

Schmidt, H.-L., Werner, R. A., and Eisenreich, W. (2003). Systematics of ${ }^{2} \mathrm{H}$ patterns in natural compounds and its importance for the elucidation of biosynthetic pathways. Phytochem. Rev. 2, 61-85. doi: 10.1023/B:PHYT.0000004185.92648.ae

Schouten, S., Ossebaar, J., Schreiber, K., Kienhuis, M. V. M., Langer, G., Benthien, A., et al. (2006). The effect of temperature, salinity and growth rate on the stable hydrogen isotopic composition of long chain alkenones produced by Emiliania huxleyi and Gephyrocapsa oceanica. Biogeosciences 3, 113-119. doi: 10.5194/bgd-2-1681-2005

Sessions, A. L., Burgoyne, T. W., Schimmelmann, A., and Hayes, J. M. (1999). Fractionation of hydrogen isotopes in lipid biosynthesis. Org. Geochem. 30, 1193-1200. doi: 10.1016/s0146-6380(99)00094-7

Sessions, A. L., Jahnke, L. L., Schimmelmann, A., and Hayes, J. M. (2002). Hydrogen isotope fractionation in lipids of the methane-oxidizing bacterium Methylococcus capsulatus. Geochim. Cosmochim. Acta 66, 3955-3969. doi: 10.1016/s0016-7037(02)00981-x

Sharma, S., Radl, V., Hai, B., Kloos, K., Fuka, M. M., Engel, M., et al. (2007). Quantification of functional genes from procaryotes in soil by PCR. J. Microbiol. Methods 68, 445-452. doi: 10.1016/j.mimet.2006.10.001

Summons, R. E., Jahnke, L. L., and Roksandic, Z. (1994). Carbon isotopic fractionation in lipids from methanotrophic bacteria - relevance for interpretation of the geochemical record of biomarkers. Geochim. Cosmochim. Acta 58, 2853-2863. doi: 10.1016/0016-7037(94)90119-8

Valentine, D. L., Chidthaisong, A., Rice, A., Reeburgh, W. S., and Tyler, S. C. (2004). Carbon and hydrogen isotope fractionation by moderately thermophilic methanogens. Geochim. Cosmochim. Acta 68, 1571-1590. doi: 10.1016/j.gca.2003.10.012

van der Meer, M. T. J., Schouten, S., Bateson, M. M., Nubel, U., Wieland, A., Kuhl, M., et al. (2005). Diel variations in carbon metabolism by green nonsulfur-like bacteria in alkaline siliceous hot spring microbial mats from Yellowstone National Park. Appl. Environ. Microbiol. 71, 3978-3986. doi: 10.1128/aem.71.7.3978-3986.2005

van der Meer, M. T. J., Schouten, S., Sinninghe Damsté, J. S., and Ward, D. M. (2007). Impact of carbon metabolism on ${ }^{13} \mathrm{C}$ signatures of cyanobacteria and green non-sulfur-like bacteria inhabiting a microbial mat from an alkaline siliceous hot spring in Yellowstone National Park (USA). Environ. Microbiol. 9, 482-491. doi: 10.1111/j.1462-2920.2006.01165.x

Wallace, L. K. (2012). Elucidation of the Biosynthetic Production Pathways of Neutral Lipids in the Marine Haptophyte Emiliania huxleyi. Master Thesis, California State University, Chico.

Wolhowe, M. D., Prahl, F. G., Probert, I., and Maldonado, M. (2009). Growth phase dependent hydrogen isotopic fractionation in alkenone-producing haptophytes. Biogeosciences 6, 1681-1694. doi: 10.5194/bgd-6-4165-2009

Zhang, X. N., Gillespie, A. L., and Sessions, A. L. (2009a). Large D/H variations in bacterial lipids reflect central metabolic pathways. Proc. Natl. Acad. Sci. U.S.A. 106, 12580-12586. doi: 10.1073/pnas.0903030106

Zhang, Z., and Sachs, J. P. (2007). Hydrogen isotope fractionation in freshwater algae: I. Variations among lipids and species. Org. Geochem. 38, 582-608. doi: 10.1016/j.orggeochem.2006.12.004

Zhang, Z., Sachs, J. P., and Marchetti, A. (2009b). Hydrogen isotope fractionation in freshwater and marine algae: II. Temperature and nitrogen limited growth rate effects. Org. Geochem. 40, 428-439. doi: 10.1016/j.orggeochem.2008. 11.002

Conflict of Interest Statement: The authors declare that the research was conducted in the absence of any commercial or financial relationships that could be construed as a potential conflict of interest.

Copyright (๑) 2015 Heinzelmann, Villanueva, Sinke-Schoen, Sinninghe Damsté, Schouten and van der Meer. This is an open-access article distributed under the terms of the Creative Commons Attribution License (CC BY). The use, distribution or reproduction in other forums is permitted, provided the original author(s) or licensor are credited and that the original publication in this journal is cited, in accordance with accepted academic practice. No use, distribution or reproduction is permitted which does not comply with these terms. 